\title{
EXPLORING NUMBAS FORMATIVE FEEDBACK FOR TEACHING AND LEARNING MATHEMATICS: AN AFFORDANCE THEORY PERSPECTIVE
}

\author{
Said Hadjerrouit and Celestine Ifeanyi Nnagbo \\ University of Agder, Institute of Mathematical Sciences, Kristiansand, Norway
}

\begin{abstract}
The purpose of this article is to explore students' and teachers' perceptions of affordances, and their actualization while interacting with the e-assessment system Numbas and its effect in terms of formative feedback delivery. The article uses affordance theory and a qualitative research design approach to analyze data using semi-structured interviews. Eight interviews were conducted with six students and two teachers. The results reveal the actualization of several affordances such as ease of use and navigation, variation in mathematical contents, congruence to textbook mathematics, support for pen and paper skills, learner autonomy and motivation to engage in mathematical problem-solving. Conclusions and future work based on comparative studies are drawn from the results to promote Numbas formative feedback for teaching and learning mathematics.
\end{abstract}

\section{KEYWORDS}

Affordance Actualization, Affordance Perception, Affordance Theory, Constraint, Formative Feedback, Numbas

\section{INTRODUCTION}

In recent years, Numbas is becoming increasingly popular due its wide acceptability and integration into mathematics education, which is evident from about thirty institutions around the world, including the United Kingdom and Norway that are currently using the software tool. Clearly, this increased attention on the use of Numbas to provide timely feedback to students learning mathematics underscores the relevance of studies on its affordances. However, except one article (Hadjerrouit, 2020b), there is a lack of research providing an understanding of affordances and constraints of Numbas as a tool of feedback delivery between teachers and students. The aim of the present study is to investigate the affordance perceptions of Numbas (as a tool of formative assessment) by teachers (who employ Numbas for feedback delivery) and students, and the associated constraints in the actualization of the affordance (Nnagbo, 2020). In specific terms, this study aims to address the following research questions: a) What affordances of Numbas are perceived by students and teachers? b) How are the affordances of Numbas actualized by students and teachers? and c) What are the constraints for the actualization of Numbas' affordances by students and teachers?

The article is structured as follows. First, Numbas is described. Second, the theoretical framework is outlined, followed by methods. Then, the results and discussion are presented. Finally, some remarks on limitations of the study and future work conclude the article.

\section{NUMBAS}

Among the most popular e-assessment systems is Numbas (a typical interface in shown in Figure 1), developed by the e-learning unit of Newcastle university's school of mathematics and statistics with focus on formative e-assessment (Lawson-Perfect, 2015). A test "consists of several questions, each of which consisting of one or more parts which assess an individual answer entered by the student” (Lawson-Perfect, 2015, p. 1). 


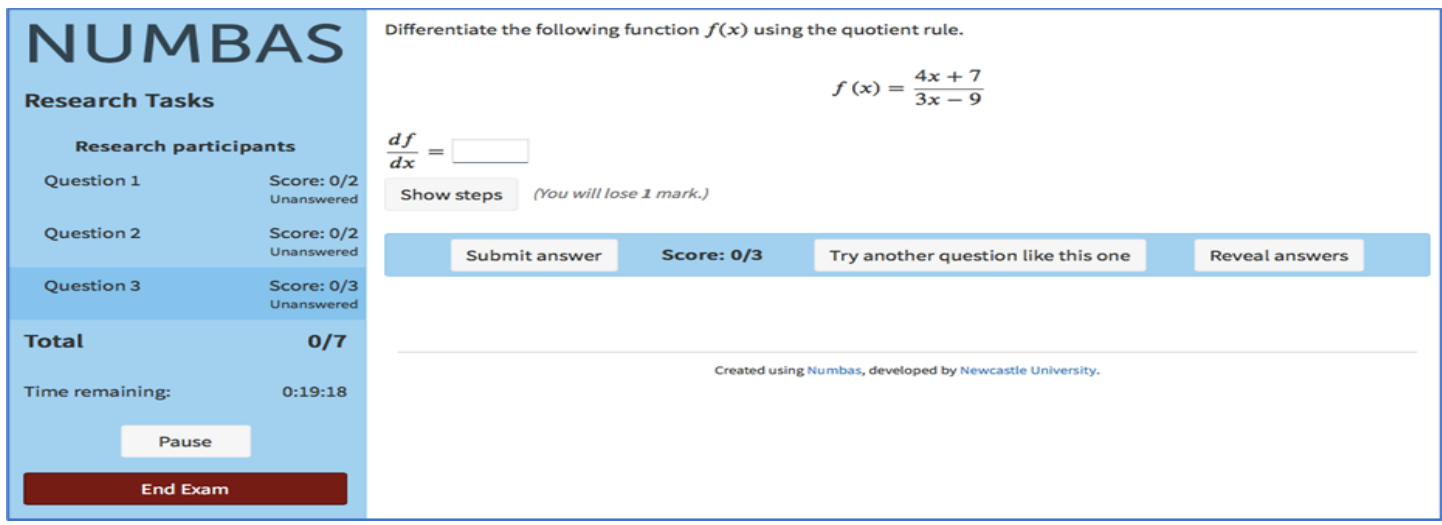

Figure 1. A typical Numbas user interface

The most important features of Numbas are as follows:

Question types - Numbas allows several question-and-answer types such as mathematical expression, Number entry, matrix entry, match text pattern, choose one from a list, choose several from a list, match choices with answers, gap-fill, information only, quantity with units, are supported by Numbas (Lawson-Perfect, 2020). Numbas shows the notation instantly beside the input field, so as students are inputting their answers in the system, simultaneously they see how the system understands their expressions (Figure 2).

$$
2 x\left(10 x-5 x^{2}+6\right)=20 * x^{\wedge} 2-10 x^{\wedge} 3+12 x 20 x^{2}-10 x^{3}+12 x
$$

Figure 2. The student's answer and how Numbas reads it

Ease of integrating rich content materials - Numbas supports videos and interactive diagrams to be embedded on the editor before they are distributed along with the final questions. The videos can be uploaded directly, while the interactive diagrams could be included in Numbas questions either by embedding a GeoGebra applet or use JSXGraph (Lawson-Perfect, 2020).

Marking - Numbas uses marking algorithm that is conceptually simple to mark mathematical expressions. For example, in factorizing a quadratic equation, expected answers are often in this form $(x+a)(x+b)$ and not $\mathrm{x}^{\wedge} 2+\mathrm{ax}+\mathrm{b}$, but Numbas marking algorithm is sophisticated enough to understand the later form, mark correctly and give feedback accordingly.

Feedback - Numbas performs marking on the client, which makes its feedback immediate. In order to make its feedback effective, there are multiple ways Numbas gives feedback to both students and instructors. These include submit answer, show steps, reveal answers, try another question like this one.

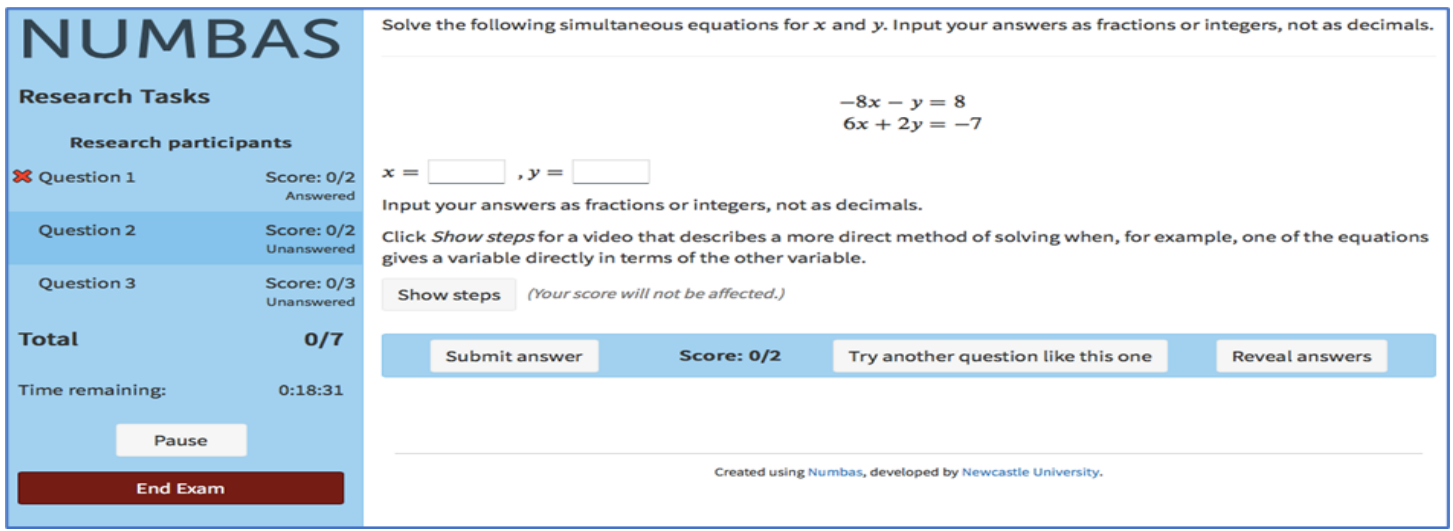

Figure 3. Feedback options

Submit answer - Students get instant feedback as soon as they submit an answer. The feedback simply indicates with a green color 'good' sign if the submitted answer is correct, with red color 'bad' sign indicating that the supplied answer is wrong, or partially correct, with feedback message underneath. The students will 
also be shown the maximum attainable score for each question, and their own score for the question after they have submitted the answer. The teacher may choose to disable these feedback options.

Show steps - When a student clicks on the show steps, Numbas will give the general solution to that question, it may include video or graphical explanation depending on the kind of feedback the examiner put in there. This is a way of reminding the student to have a look at the formula or the general solution and retry solving the task. Show steps does not give students the exact solution to the particular task.

Try another question like this one - Numbas uses the set of variables defined by arbitrary mathematical expressions to randomly generate questions that are similar. With this, student have the opportunity to attempt similar questions many times until they feel confidence enough to move to the next question.

Reveal answer - This section provides step by step solution that is personalized to the question randomly generated question to the student. When a student decides to explore this option, they lose all the marks and cannot re-attempt the exact question. Again, the instructor may decide to disable this.

Statistics - Numbas stores data of students' performance. This statistical package is particularly helpful to the teachers. They can track how well the students understand the topic through their performances, and they can equally identify the tasks students perform below expectations and reemphasis on them in the next class.

\section{THEORETICAL FRAMEWORK}

The term 'affordance' was coined by James J. Gibson, a perceptual psychologist, in his book titled 'the Ecological Approach to Visual Perception', first published in 1977. He proposed the term to describe what the environment offers the animal (Gibson, 1986, p. 127). He argued that affordance can be seen from the properties of the environment that are relative to the animal in question. He further stresses that affordance must be peculiar to the animal it affords; not just any property of the environment or whatever the environment can offer. Affordances can be both objective and subjective, "they are objective because they exist independently of the act of perception, but they are also subjective because the frame of reference is the individual's action capabilities" (Osiurak, Rossetti, \& Badets, 2017).

The term "affordance" in the world of Human-Computer Interaction (Norman, 1988) refers to a goal-oriented action potential that emerges as result of interaction between subjects (e.g., students and teachers) and an object (e.g., Numbas). This perspective is in accordance with the conceptualization of affordance by Strong et al. (2014) who defined it as "the potential for behaviors associated with achieving an immediate concrete outcome and arising from the relation between an artifact and a goal-oriented actor or actors" (p. 69). Affordance is neither the property of an object in isolation nor that of the subject. Instead, it emerges as an offshoot of a dynamic interaction between the subjects (students and teachers) and the object (Numbas). It is perceived (i.e., students and teachers are aware of the existence of the action potential of Numbas) in many ways and actualized (i.e., students are able to turn the potential of Numbas into action) to produce effect (i.e., feedback delivery) depending on many factors that include the Numbas platform, its user interface, capability of the students, and their level of preparedness (Markus \& Silver, 2008). Moreover, the actualization of Numbas affordance is either facilitated by some enabling conditions or mitigated by some constraints.

Given the emergence of the Numbas affordance, it is legitimate to ask how the affordance is perceived. As such, when students interact with Numbas to facilitate feedback delivery on some mathematics concepts they do so conveniently with the aid of the technical features of the software. During this process, they become aware of the affordance that emerged during the interaction in terms of feedback delivery. The next issue is how they can actualize this affordance. Yet, this issue raises three questions: (a) How do action potentials turn into actions? (b) Are the perception and actualization processes distinct? (c) Does an action potential necessarily need to be perceived before being actualized?

Affordance actualization is a process of turning action potentials (affordances) into real actions to bring an effect in using a particular tool (Anderson \& Robey, 2017; Bernhard et al., 2013). In specific terms, affordance actualizations are "the actions taken by actors as they take advantage of one or more affordances through their use of the technology to achieve immediate concrete outcomes in support of organizational goals" (Strong et al., 2014, p. 70). To turn a possibility into an action, it is expected that the user has the ability and capability to harness the potential and there are enabling conditions to facilitate the process. Affordance actualization varies from one individual to another because it is goal-oriented and a process of specificity. As Volkoff and Strong (2017) wrote "actualization relates to a particular individual actor and details regarding the specific actions that actor will take or has taken" (p. 236). Two or more students may interact with Numbas, for instance, and actualize different affordances of the software depending on their respective individual differences and choices. 
Some researchers maintain that the two processes are the same and by implication affordance may be actualized without being perceived (Strong et al., 2014; Volkoff \& Strong, 2013; Wang et al., 2018). In contrast, some other researchers maintain that actualization is a different process from perception of affordance, as such, affordances are perceived before being actualized (Anderson \& Robey, 2017; Bernhard et al., 2013; Pozzi et al., 2014; Thapa \& Sein, 2018). This study acknowledges that affordance perception and actualization are two distinct processes, and, in most cases, affordances are perceived before being actualized as shown in Figure 4. Anderson and Robey (2017, p. 102) summarizes this line of thought: "Affordance actualization in practice is not fully explainable through perception and goals alone because there are times when a user is both aware of an affordance and has a current goal that the affordance could support, and yet the affordance is not actualized".

Moreover, it is expected that following the actualization of Numbas affordance are some consequences (effects). These consequences as Bernhard et al. (2013) put it may be "intended by the user and/or those by the original creator of the artefact as well as unintended effects" (p.6). It is important to remark that the perception and actualization of affordances happen very fast, which could be a reason why a clear distinction is not easy to sustain. It is expected that when affordances are perceived and then actualized, then some effects are generated in terms of feedback delivery on mathematical tasks to students. Figure 4 shows the underlying framework that captures the perception, actualization of Numbas affordance, and its effect.

Affordance $\longrightarrow$ Perception $\longrightarrow$ Actualisation $\longrightarrow$ Effects

Figure 4. A framework for perception, actualization of Numbas affordance, and its effect

Based on these considerations, this study proposes a framework for assessing Numbas affordances. The framework encompasses the following layers: (a) Technological affordances at the ergonomic level; (b) Pedagogical affordances at three levels: Assessment, mathematics subject, student/mathematics tasks/classroom; and (c) Socio-cultural affordances at the teacher education level. The framework (Figure 5) relies basically on Hadjerrouit (2020a) for the conceptualization of its constituent parts.

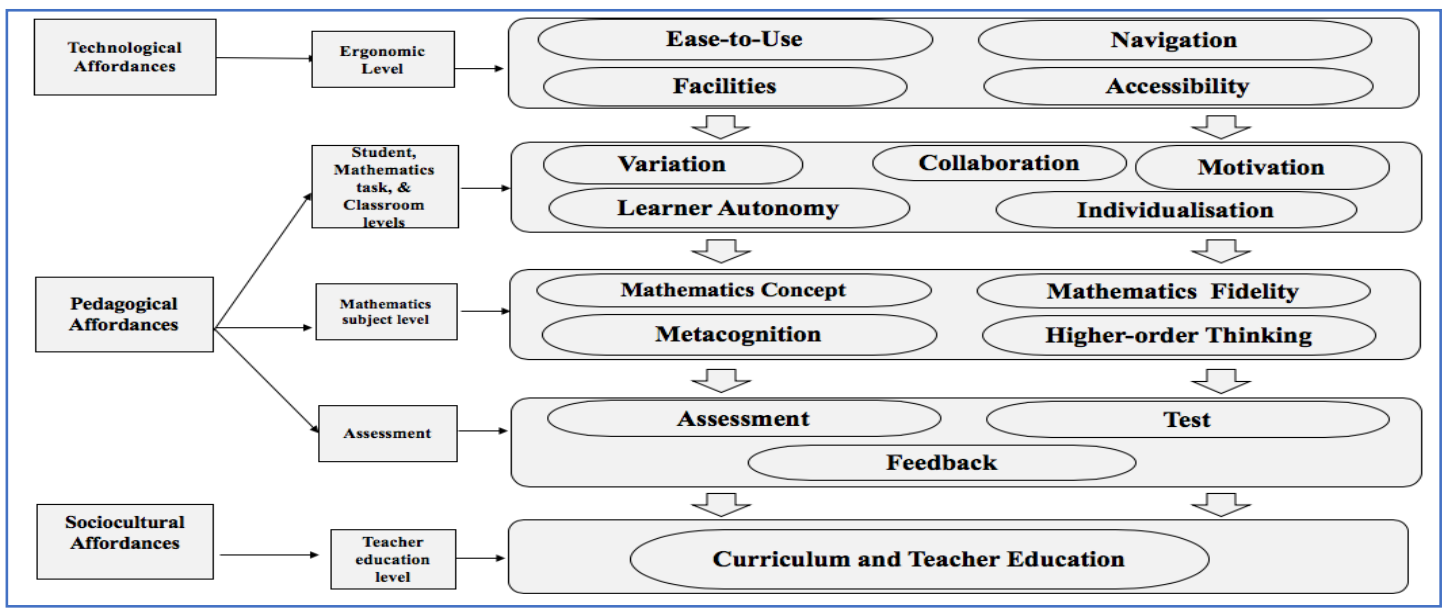

Figure 5. Framework for assessing Numbas affordances and constraints

\section{METHODS}

A case study design approach is chosen to understand and analyze the affordances perceived by both students and teachers while interacting with Numbas, how they actualized the perceived affordances, and the relevant criteria for the actualization. A case study involves "detailed examination of one setting, or one single subject, (...), or one particular event" (Bogden \& Biklen, 1982, p. 58). A case study is the preferred strategy to answer 'how' and 'why' questions, as well as the type of 'what' questions that are expository in nature (Yin, 2009). Thus, these are in line with the research questions of this study. 


\subsection{Participants}

The data collection was done from two set of participants - Two teachers and six students from a mathematics teacher education class of a Norwegian university. The two teachers were considered and selected because they are actively making use of Numbas for formative assessment in their respective classes. The second cohort is six out of about twelve students from one class who willingly volunteered to participate in the study. These participants are master's degree students. They were currently taking a course entitled "Digital tools in mathematics teaching". Both cohorts were familiar with Numbas and affordance theory.

\subsection{Data Collection and Analysis Methods}

Prior to data collection by means of interviews, a survey questionnaire was used to collect information based on the categories of the theoretical framework for assessing Numbas affordances and constraints (Figure 5). The students' responses to the questionnaire were then used to inform the subsequent interview guide and associated questions in relation to the theoretical framework.

A thematic approach is used to analyze the empirical data by identifying, analyzing, and reporting codes and themes within the data set (Bryman, 2016). Code development takes a deductive-inductive strategy based on the interplay between the empirical data and the pre-defined categories of the framework. The analysis starts with a deductive approach based on the categories of the framework in search for meaningful interpretation of the empirical data following an inductive approach. An example of coding is as follows:

Pre-defined categories from the theoretical framework (Figure 5): Assessment, Test, and Feedback

Deductive approach: Use these pre-defined categories about the feedback Numbas offers to the participants, which includes feedback when teachers are creating tasks and during the period students are solving tasks.

Inductive approach based on empirical data: (...) first you can show steps, which show you how you are supposed to do it, not how you supposed to solve that same task, just general solution and general set of rules, and afterwards you can see then the actual solutions, if you want to (...)

As the process evolves, room was given for the data to express itself by creating new codes that emerged from the data inductively. The development of inductive codes follows reading and rereading of the data carefully and annotating same to identify topics raised by participants themselves. The topics (codes) are refined and validated by checking whether these are repeated by different participants or highlighted by the participants themselves as an important theme (Hennink et al., 2020).

\section{RESULTS}

\subsection{Summary of Results}

The findings show that many affordances that emerged were perceived and actualized while some were not actualized at all or partially actualized due to some constraints. Firstly, most students perceived and actualized the technological affordances while interacting with Numbas. They also indicated that they were motivated when they used Numbas. They attributed their motivation to clean interface and good feedback. Furthermore, they think that they can work on Numbas independently but that heavily relies on how comprehensive the feedbacks are. The role of teachers to make these feedbacks was pointed out. Most students believed that collaboration and differentiation are low in Numbas, but that the teacher can make them work by asking the students to work in groups using one computer and creating different levels of tasks that will target different learning abilities of their students. They also expressed that their pen and paper skills develop simultaneously while using Numbas. Finally, they think Numbas can be adapted as part of digital tools in Norwegian schools, specifically for assessing procedural understanding.

Secondly, all the teachers indicated that the technological affordances were perceived and actualized, except the editor's interface which they think is easy to make simple tasks and difficult to make complex tasks. Teachers also agreed that the elements of pedagogical affordances were globally perceived and actualized. 
They reported that students are motivated to engage in Numbas due to the instant feedback and other feedbacks. Furthermore, they expressed high satisfaction with the feedback they receive from Numbas in form of statistics of students' activities. Moreover, teachers believed that Numbas cannot guarantee total autonomy. Finally, a constraint also was actualized in the form of wrong marking of some correct answers, though in rare occasions, but this was found to provoke deep mathematical thinking in most of students.

Thirdly, the findings suggest that students and teachers are on the same page in most of the affordances and constraints of Numbas, except for ease of use, learner autonomy and suitability to the new core curriculum. While teachers found Numbas difficult to create 'very good' tasks, students found the user interface simple to use. Teachers further think that their role cannot be replaced by Numbas. Students believed that with comprehensive feedback, they can work independently on Numbas. Teachers are indecisive about adopting Numbas to the Norwegian schools, but the students indicated that Numbas is suitable to part of the digital tools, where it will be used for testing procedural understanding.

\subsection{Affordance Emergence, Perception, Actualization, and Effect of Feedback}

The goal of this study is to explore how Numbas promotes formative assessment for mathematics teaching and learning by assessing the affordances and constraints that emerge from interactions between teachers/students and Numbas. Having addressed Numbas affordances and constraints (Research question 1 and 2), the next question, which this paper addresses is how these affordances do, from teachers' and students' views, promote formative assessment, and ultimately mathematics teaching and learning. According to the theoretical framework, the actualization of Numbas affordances lead to some effects for teaching and learning of mathematics as a result of formative feedback delivery to the user. The essence of formative assessment is to receive formative feedback that will lead to improvement in teaching and learning. Therefore, formative feedback is vital to improving mathematics teaching and learning (Pereira et al., 2016).

However, the desired goal (formative feedback delivery) does not manifest straight away. In fact, it manifests as a consequence or effect of the actualized affordances. Figure 4 explains this relationship. It shows that achieving the goal (formative feedback delivery) that is needed to improve teaching and learning of mathematics subject depends on perception and actualization of the emerged affordances of Numbas by the students or teachers. If they fail to actualize the affordances, the intended goal may not be achieved.

While the goal of students is to receive feedback from teachers through Numbas. Therefore, formative feedback delivery is the common goal, but the ultimate goal, which is the implication of the formative feedback delivery is to improve teaching and learning of mathematics subjects. From the model, the desired goal (formative feedback delivery) does not manifest straight away. It manifests as a consequence or effect of actualization of Numbas affordances. Recall that the emergence of Numbas affordance is viewed as an offshoot of a dynamic relationship between students/teachers and Numbas, and perception of the emerged affordances concerns its awareness by students/teachers. Whereas actualization is the action taken by the students/teachers to take advantage of the perceived affordances.

When the students/teachers actualize some required affordance(s), then the effect will lead to achieving the goal (formative feedback delivery) and by extension improves teaching and learning. For example, when a student wants to solve formative assessment at home using Numbas, her goal is to achieve formative feedback through Numbas. However, she must first actualize the affordance of accessibility. If the student faces constraint of internet connection, then the effect will be that she will not achieve her goal (formative feedback delivery) because she could not actualize an important affordance required. But if the student actualizes the affordance by accessing the internet, she may achieve the goal, however this is subject to actualizing other feedbacks (e.g., ease of use, navigate) she might also need to successfully achieve the goal.

\section{DISCUSSION}

The results reveal that first, both teachers and students globally share the same views regarding technological affordances of Numbas. They perceived and actualized ease of use, ease of navigation, accessibility, and facility's affordances of Numbas. The effect of this is that the students' engagement increased; they became motivated to solve more formative assessment tasks in Numbas. The number of times they are allowed to attempt a related task is unlimited. There was no barrier (except lack of Internet) regarding where and when 
they will solve formative assessment and receive feedback in Numbas. Ultimately, this would lead to improved learning of mathematics. This clearly shows and supports the study finding that technological affordances support pedagogical affordances (Pierce \& Stacey, 2010). Pedagogical affordances of any digital tool depend to a large extent on the technological affordances of such tool. If students or teachers find for example the interface of a tool difficult to use, they may likely not use the tool to achieve their pedagogical purpose. One has to find the interface friendly before he/she can use it to learn. If the navigation buttons are hidden, the user might not be able to move to the feedback pages thereby not getting the desired help.

Second, both teachers and students perceived and actualized several pedagogical affordances. They found Numbas to support different mathematical content presentations. With this, teachers can create formative assessment in different representations - diagrams, graphs, matrices, multiple choices etc., also they can create the associated feedbacks in various forms that may cover the students' misconceptions. Formative feedbacks that Numbas give are found useful and motivating by the teachers and students. The main essence of formative assessment according to Weeden et al. (2002) is to identify students' current performance and aid learning, and that one of the ways teachers can achieve this important objective is through feedbacks. This is the reason why formative feedback is done while Numbas is on-going. It is to identify how far the objectives and goals of a tool have been achieved. Teachers and their students mostly undertake this kind of assessment to obtain vital information in form of formative feedback that they will apply to modify and improve the ongoing teaching and learning activity (Black \& William, 2010).

The feedback in form of statistics containing students' performance identifies their current performance level, areas of difficulties, strengths and many more, are useful to the teachers for conducting diagnostic teaching. More so, feedbacks from teachers to students regarding their performances, challenges and difficulties are aimed at encouraging and helping them to identify their misunderstandings and misconceptions regarding the topics and concepts and ways to improve. Many studies have link feedback as one the most powerful ways to increase students learning and achievement (Hattie \& Clarke, 2018; Hattie \& Timperley, 2007). However, delivering it on time is often challenging to the teachers. Findings from this present study reveal that Numbas promotes formative assessment by providing feedback to both students and teachers in a timely fashion. Students receive feedbacks in different forms including instants feedbacks, hints, reveal answers, etc. It provides feedbacks to the teachers in form of the statistical report of the students' activities. With this, enormous time is saved for both the teachers and students.

Formative assessment requires setting learning and monitoring progress towards achieving the goals. This type of regularity in feedback provision helps to achieve learning goal. Findings also reveal that engagement in Numbas enhances students' motivation and increases their mathematical engagements. Students identified among others, the instant feedback to be very motivating. Furthermore, teachers expressed satisfaction that Numbas could save them a whole lot of time. Numbas is equipped with randomization mechanisms. That means, it can generate unlimited similar tasks with corresponding feedbacks. This saves teachers a lot of time and stress. They need not spend hours and days preparing tasks for formative assessment. It also offers students the opportunity to solve many tasks until they master the topic.

\section{CONCLUSION}

This work is a case study on formative assessment from a mathematics teacher education class using Numbas. It entails in-depth study of one setting. Affordances and constraints of Numbas have been studied in detail using a semi-structured interview, which gave the participants the opportunity to fully express their thoughts. However, the study is not without limitations. Firstly, the participants $(N=8)$ are master's students and their teachers from teacher education program of one university. A larger number of participants from one or several classes and universities could have been more desirable to make better generalization and ensure more validity and reliability. However, the chosen number of participants with a large set of qualitative information seems to be justifiable for addressing the research questions and issues critically. The second limitation has to do with the student participants who are not the 'end users' of Numbas. Though they have good knowledge of Numbas and affordance theory, they have studied Numbas in details, used it for assessment (but in a limited form), also they have studied and evaluated other current digital tools in mathematics education. However, it will be difficult to take their opinions and perceptions to pass judgement for students who use Numbas regularly for studies. The findings can be drawn in the light of the use of Numbas in teacher education program. Students 
using Numbas for day-by-day activities may have a different perspective about the affordance perception and actualization processes. Future research studies involving such set of students would be appropriate to compare with findings of the presents study.

\section{REFERENCES}

Anderson, C., \& Robey, D. (2017). Affordance potency: Explaining the actualization of technology affordances. Information and Organization, 27(2), pp.100-115.

Bernhard, E., Recker, J., \& Burton-Jones, A. (2013) Understanding the actualization of affordances: A study in the process modeling context. In M. Chau, \& R. Baskerville (Eds.) Proceedings of the 34th International Conference on Information Systems (ICIS 2013). Association for Information Systems (AIS), pp. 1-11.

Bogden, C. R., \& Biklen, S. K. (1982). Qualitative Research for Education: An Introduction to Theory and Methods, Boston: Ally and Bacon. In: Inc.

Bryman, A. (2016). Social research methods. Oxford, United Kingdom: Oxford University Press.

Gibson, J. J. (1986). The ecological approach to visual perception. Hillsdale, N.J: Lawrence Erlbaum.

Hadjerrouit, S. (2020a). Exploring the affordances of SimReal for learning mathematics in teacher education: A Socio-cultural perspective. In L. H. Chad; S. Zvacek; \& J. Uhomoibhi (2020). Computer Supported Education. 11th International Conference, CSEDU 2019, Heraklion, Greece. Revised Selected Papers. Springer Nature, pp. 26-50.

Hadjerrouit, S. (2020b). Exploring the affordances of Numbas for mathematical learning: A case study. International Network for Didactic Research in University Mathematics (INDRUM 2020), pp. 453 - 462.

Hattie, J., \& Clarke, S. (2018). Visible learning: Feedback. London: Routledge.

Hattie, J., \& Timperley, H. (2007). The power of feedback. Review of Educational Research, 77(1), pp. 81-112.

Hennink, M., Hutter, I., \& Bailey, A. (2020). Qualitative research methods. SAGE Publications Limited.

Lawson-Perfect, C. (2015). A demonstration of Numbas, an e-assessment system for mathematical disciplines. CAA Conference. Retrieved from https://www.numbas.org.uk/blog/2015/07/a-demonstration-of-numbas-at-caa-2015/

Lawson-Perfect, C. (2020). How Numbas can help during the COVID-19 crisis. Retrieved from

https://www.numbas.org.uk/blog/2020/03/how-numbas-can-help-during-the-covid-19-crisis/

Markus, M. L., \& Silver, M. S. (2008). A foundation for the study of IT effects: A new look at DeSanctis and Poole's concepts of structural features and spirit. Journal of the Association for Information Systems, 9(10), pp. 609-632.

Nnagbo, C. I. (2020). Assessment in mathematics education using Numbas: Affordances and constraints from an activity theory perspective. [Unpublished master's thesis]. University of Agder, Kristiansand, Norway.

Norman, D. A. (1988). The psychology of everyday things. New York: Basic Books.

Osiurak, F., Rossetti, Y., \& Badets, A. (2017). What is an affordance? 40 years later. Neuroscience and Biobehavioral Reviews, 77, pp. 403-417.

Pereira, D., Flores, M. A., Simão, A. M. V., \& Barros, A. (2016). Effectiveness and relevance of feedback in Higher Education: A study of undergraduate students. Studies in Educational Evaluation, 49, pp. 7-14.

Pierce, R., \& Stacey, K. (2010). Mapping pedagogical opportunities provided by mathematics analysis software. International Journal of Computers for Mathematical Learning, 15(1), pp. 1-20.

Strong, D. M., Volkoff, O., Johnson, S. A., Pelletier, L. R., Tulu, B., Bar-On, I., ... Garber, L. (2014). A theory of organization-EHR affordance actualization. Journal of the Association for Information Systems, 15(2), pp. 53-85.

Volkoff, O., \& Strong, D. M. (2013). Critical realism and affordances: Theorizing IT-associated organizational change processes. MIS Quarterly, 37(3), pp. 819-834.

Volkoff, O., \& Strong, D. M. (2017). Affordance theory and how to use it in IS research. In R. D. Galliers \& M.-K. Stein (Eds.). The Routledge companion to management information systems. London: Routledge.

Wang, H., Wang, J., \& Tang, Q. (2018). A review of application of affordance theory in information systems. Journal of Service Science and Management, 11(1), pp. 56-70.

Weeden, P., Winter, J., \& Broadfoot, P. (2002). Assessment. London: RoutledgeFalmer.

Yin, R. K. (2009). Case study research: Design and methods, 4th ed., vol. 5. Applied social research methods series. 